\title{
AULAS DE CAMPO COMO INSTRUMENTOS PARA DIFUSÃO DA SUSTENTABILIDADE
}

\author{
SILVA, Giovana Dominicci1'; MARINHO, Agnês de Oliveira²; MACHADO, Micheli \\ Kowalczuk ${ }^{3}$; HOEFEL, João Luiz de Moraes ${ }^{4}$.
}

\section{Resumo}

A busca pela sustentabilidade é um desafio para a sociedade global. Neste sentido, é fundamental proporcionar meios para que os indivíduos realmente compreendam a complexidade da problemática ambiental para que desta forma possam perceber e desenvolver uma interação mais equilibrada entre o ser humano e o meio ambiente. Para tanto existem várias maneiras de promover processos de aprendizagem para o desenvolvimento sustentável. Assim, este artigo apresenta a análise da percepção dos alunos sobre as experiências e lições práticas em ambientes naturais, promovidas pelo programa de ensino superior do Curso Tecnológico em Gestão Ambiental do Centro Universitário UNIFAAT. Tais atividades permitiram uma melhor compreensão do que é abordado em aulas e proporcionam experiências transformadoras na vida pessoal dos estudantes e em sua carreira profissional como gestores ambientais.

Palavras-chave: Sustentabilidade. Aulas de campo. Transtorno do Déficit de Natureza.

\begin{abstract}
The sustainability search is a challenge for global society. In this sense, it is essential to provide means for individuals to understand truly the complexity of environmental issues so that they can perceive and develop a more balanced interaction with the environment. To this end, there are several ways to promote learning processes for sustainable development. Thus, this article presents the analysis of the students' perception about the experiences and practical lessons in natural environments, promoted by the higher education program of the Technological Course in Environmental Management of UNIFAAT University Center. These activities allowed a better understanding of what is analysed in classes and provide transformative experiences in students' personal lives and their professional career as environmental managers.
\end{abstract}

Keywords: Sustainability. Field classes. Nature Deficit Disorder.

\footnotetext{
${ }^{1}$ Bióloga, mestre em Ciências da Engenharia Ambiental pela Universidade de São Paulo e pós-graduada lato sensu em Gestão Ambiental e Sustentabilidade. Foi bolsista de Treinamento Técnico nível III FAPESP do NEPAM / UNICAMP e do Centro de Estudos Ambientais - Sociedades e Naturezas da Universidade São Francisco. Atualmente é docente do Centro Universitário UNIFAAT.

${ }^{2}$ Tecnóloga em Gestão Ambiental pelo Centro Universitário UNIFAAT.

${ }^{3}$ Doutora em Ciências ESALQ/USP, Professora e Pesquisadora do Centro Universitário UNIFAAT.

${ }^{4}$ Doutor em Ciências Sociais IFCH/UNICAMP, Professor do Centro Universitário UNIFAAT e Coordenador do Núcleo de Estudos em Sustentabilidade e Cultura (NESC/CEPE/UNIFAAT)
} 


\section{Introdução}

Durante a evolução do modo de vida humana diversas mudanças se propagaram, entre elas o aumento de áreas urbanas e a ida de diversas famílias rurais para centros urbanos em busca, principalmente, de uma melhor qualidade de vida, emprego e moradia. Essa mudança ocorreu em meados dos séculos XIX e XX com evidência após a Revolução Industrial (PAULO, 2010).

Essa realidade, conhecida como êxodo rural, viabilizou um aumento dos centros urbanos através de uma ocupação desordenada e muitas vezes sem planejamento, gerando diferentes problemas socioambientais (PAULO, 2010). Dentre estes problemas é possível destacar a precariedade em saneamento básico, o mau gerenciamento dos cursos hídricos, a ocupação em áreas de risco e a diminuição das áreas verdes, fatores que têm prejudicado a saúde humana como um todo.

A degradação da saúde humana é derivada da carga excessiva de diversos problemas ambientais, devido às ações antrópicas que por anos modificaram o espaço natural, sendo que a remoção do que é natural dos espaços urbanos e a falta de integração das pessoas com o ambiente inviabiliza a ligação dos seres humanos com aquilo que vem da natureza. Neste contexto, Barbosa (1998) relata que a qualidade de vida das pessoas está diretamente ligada à necessidade de um ambiente ecologicamente equilibrado, que não envolve apenas qualidade de moradia, condições humanas de trabalho, acesso à saúde, mas implica também nas questões sociais e conexão com o ambiente natural.

As áreas naturais possuem papel fundamental e servem como uma ferramenta de grande relevância por promoverem serviços ecossistêmicos (ambientais, culturais, socioeconômicos, educacionais e estéticos), sendo que estes benefícios se integram e promovem um conjunto de ações benéficas ao ser humano. Estes benefícios são percebidos em maior intensidade quando estas áreas estão localizadas em grandes centros urbanos, podendo ser utilizadas como ferramentas de aproximação e (re) conexão entre seres humanos e áreas naturais, além de promoverem a tomada de decisão com relação às medidas de conservação em benefício à qualidade de vida e ao equilíbrio ecológico (PELLIN et al, 2014).

Neste contexto, Louv (2016) traz o conceito "Transtorno de Déficit de Natureza" (TDN), que retrata a falta de vivência das crianças em meio à natureza e o quanto é importante essa interação com o ambiente natural, pois ela permite diversos benefícios à saúde que 
influenciarão diretamente na vida adulta, como forma de prevenção de doenças físicas e mentais em longo prazo.

Schultz et al (2004) aprofundaram esta questão em um estudo que demonstra que o tipo de preocupação que uma pessoa desenvolve sobre questões ambientais está associado ao grau com que as pessoas acreditam que fazem parte da natureza. Este estudo envolveu 160 graduandos da California State University, San Marcos, e foi baseado no Implicit Association Test (IAT). Entre outros resultados, os autores destacam a importância de se conectar com a natureza na compreensão das atitudes ambientais e que é mais fácil para os participantes se conectarem aos ambientes naturais do que aos ambientes construídos. Schultz et al (2004) oferecem uma breve reflexão sobre a educação como promotora de conexão com a natureza, que permite obter resultados mais duradouros.

Vale ressaltar que existem várias maneiras de promover processos de aprendizagem para o desenvolvimento sustentável e a interação das pessoas com um ambiente natural. Dessa forma, Tilbury (2011) destaca os processos de aprendizado comumente aceitos, alinhados à Educação para o Desenvolvimento Sustentável (EDS) e que devem ser promovidos por meio de programas e atividades relacionadas com este tema.

Tilbury (2011) identificou que certos processos-chave sustentam estruturas e práticas de Educação para o Desenvolvimento Sustentável (EDS). Estes incluem processos de colaboração e diálogo (incluindo diálogos interculturais e entre partes interessadas); processos que envolvem o 'sistema inteiro'; processos que inovam o currículo, bem como experiências de ensino e aprendizagem; e processos de aprendizagem ativa e participativa.

Entre os diversos processos de aprendizado ativo e participativo analisados por Tilbury (2011), é possível mencionar discussões em grupo, debates, uso de incidentes críticos, estudos de caso, relatos reflexivos sobre papéis pessoais, atitudes e responsabilidades, leitura e escrita críticas, aprendizagem baseada em problemas concretos, trabalho de campo e aprendizagem ao ar livre.

Há evidências, como mencionado por Tilbury (2011), de que aulas e experiências ao ar livre são importantes para entender a sustentabilidade e promover o aprendizado ativo. A aprendizagem ao ar livre pode acontecer de diferentes maneiras e métodos em todas as faixas etárias, e é o foco deste artigo sobre processos de aprendizagem para o desenvolvimento sustentável, considerando, no entanto, que existem outras metodologias e formas para atingir esse mesmo objetivo. 
De acordo com Priest (1999), existem diversas empresas, escolas, universidades e organizações governamentais que utilizam aulas ao ar livre como parte de seus processos de educação e treinamento. Essa é uma questão contraditória, uma vez que a sociedade passou centenas de anos tentando encontrar maneiras de tornar a vida mais fácil e menos conectada à natureza, mas agora ela procura projetar e implementar programas e modelos que visam a trazer essa conexão de volta. Essa mudança ocorre porque o mundo está se tornando cada vez mais consumista e materialista e, dessa forma, criatividade, autoexpressão e relacionamentos estão se distanciando da vida em sociedade.

\section{Objetivos}

Este artigo tem como objetivos analisar a percepção dos alunos sobre as experiências e lições práticas em ambientes naturais, promovidas pelo programa de ensino superior do Curso Tecnológico em Gestão Ambiental do Centro Universitário UNIFAAT (HOEFEL et al, 2017). Essas atividades propuseram inicialmente uma conexão com diferentes ambientes naturais, permitindo uma melhor compreensão do que é abordado em aulas e, consequentemente, proporcionam experiências transformadoras na vida pessoal dos estudantes e em sua carreira profissional como gestores ambientais.

\section{Referencial Teórico: Sustentabilidade, qualidade de vida e o transtorno do déficit de natureza}

Os sinais que o ambiente apresenta ao ser humano, como mudanças climáticas, intensificação de eventos meteorológicos extremos, extinção de fauna e flora, têm promovido a percepção de que é importante a discussão sobre temas ambientais que possibilitem medidas de minimização de eventos destruidores, e esses eventos ocorrem devido às intervenções realizadas ao decorrer de séculos pelos seres humanos (AMARAL; GUTJAHR, 2011). Sendo assim, é preciso estabelecer uma conexão e estreitar a relação que o ser humano tem com o meio ambiente e lhe mostrar medidas acessíveis e viáveis economicamente que lhe permitem viver com melhor qualidade de vida, além de diminuir agressões ao meio ambiente (ARAÚJO; SILVA, 2004).

Desta forma, "a sustentabilidade tem se tornado, assim, um dos conceitos centrais entre grandes preocupações sobre o destino da Terra e de seus ecossistemas" (TOWNSEND et al, 2006 apud SUAREZ et al, 2010, p. 136), pois se aplica a diversas necessidades humanas, promovendo uma melhor relação entre o ser humano e o ambiente, como por exemplo, as 
construções sustentáveis, alimentação saudável, transportes menos poluentes, entre outras necessidades, promovendo novos conceitos e transformando os padrões atuais de consumo (SUAREZ et al, 2010).

Suarez et al (2010, p.136) pontuam que:

[...] denominar uma atividade de sustentável significa assumir que ela pode ser continuada ou repetida em um futuro previsível, sem causar danos à sociedade e ao ambiente. Portanto, a preocupação surge porque grande parte das atividades humanas é insustentável.

Entretanto, a sustentabilidade não se emprega apenas a situações contemporâneas, ela pode ser desenvolvida principalmente em áreas naturais, que podem ou não estar em territórios urbanos (GUIMARÃES; PELLIN, 2015). Neste sentido, a Organização das Nações Unidas lançou uma agenda de ações denominada "Transformar o nosso mundo: Agenda 2030 de Desenvolvimento Sustentável", que tem como objetivo central melhorar a qualidade de vida das pessoas, pautando suas principais ações na erradicação da pobreza, na promoção da prosperidade e na geração de bem-estar humano (ONU BR, 2018). Esta agenda é formada por 17 grandes objetivos, desmembrados em 169 metas, que foi aprovada em 25 de setembro de 2015 e entrou em vigor a partir de 01 de janeiro de 2016 e aborda com grande relevância questões ambientais, como agricultura sustentável, ações para melhorar a qualidade de vida e o bem-estar humano, uma gestão abrangente do saneamento sustentável que possa atingir inclusive populações que vivem em regiões mais remotas e de baixa renda.

Ressalta também a importância de proporcionar acesso a energias limpas condizentes com a realidade financeira das famílias ao redor do mundo, permitir acesso a trabalho em condições adequadas, incentivar padrões de consumo sustentáveis, medidas para redução na intensificação das mudanças climáticas, promover interesse à conservação e preservação de ambientes naturais, dando condições de maiores possibilidades de equilíbrio ecológico. De um modo geral, a agenda tem como principal finalidade integrar a vida humana ao meio ambiente, priorizando uma relação equilibrada para esta e futuras gerações.

É importante ressaltar que os objetivos se dissipam em diversos setores da vida humana, mas sempre procurando fortalecer as conexões existentes entre o ser humano e natureza, pontuando a importância do meio ambiente em todas as esferas de necessidade humana (ONU BR, 2018). Esta agenda ainda ressalta a importância do contato dos seres humanos com o ambiente, evidenciando os diversos benefícios e a melhoria na qualidade de vida das pessoas quando ocorre um maior contato com áreas naturais (ONU BR, 2018). 
Neste contexto, cabe mencionar o conceito de serviços ecossistêmicos, que são benefícios gerados por áreas naturais e seus componentes/integrantes, e que estão diretamente ligados à melhoria da qualidade de vida e do bem-estar humano (Avaliação Ecossistêmica do Milênio, 2003).

Guimarães e Pellin (2015) relatam que moradias próximas a espaços verdes conservados promovem benefícios diretos à saúde humana e que populações localizadas no entorno destes espaços são menos tendenciosas a desenvolverem doenças psicológicas.

Mesmo com a crescente discussão da importância do contato com o meio ambiente e de que esta conexão permite uma evolução saudável na vida de uma criança e de um adulto, ainda assim, persiste um distanciamento gradativo da sociedade das áreas naturais, dificultando ações de conservação, pelo fato de que parte da sociedade não compreende os benefícios derivados de ambientes naturais conservados para o bem-estar social, e que é gerado por estas áreas (SILVA; SAMMARCO, 2015).

De acordo com Maller et al. (2006), a enorme destruição que as atividades humanas geraram nos ecossistemas promoveu uma compreensão da importância do ambiente natural para a qualidade de vida dos seres humanos. Essa visão reconhece que plantas e animais (incluindo humanos) não existem como entidades independentes, mas fazem parte de ecossistemas complexos e interconectados. Assim, os ecossistemas são um capital fundamental do qual toda a vida depende e fica claro que a natureza e os ambientes naturais estão relacionados à saúde e ao bem-estar humano. Buscar a saúde e a sustentabilidade humanas sem considerar a importância da sustentabilidade ambiental envolve atrair consequências potencialmente devastadoras para a saúde e o bem-estar de populações inteiras.

Neste contexto, é perceptível a degradação da saúde humana vinculada ao distanciamento do ambiente natural e é neste contexto que o conceito "Transtorno de Déficit de Natureza" começou a ser discutido em 2005 por Richard Louv, por meio do seu livro "Last Child in the Woods: Saving Our Children From Nature-Deficit Disorder”, que aborda as preocupações que levaram os profissionais de diversas áreas a se perguntar o que os novos modos de vida estão trazendo de malefícios para as novas gerações.

No entanto, estudos apontam que vários fatores podem influenciar esse déficit, não apenas a distância da natureza, mas também as deficiências de saúde causadas por essa desconexão (KUO, 2013; DWYRE, 2015). Para uma nova geração de crianças, as experiências diretas com áreas naturais, seja no quintal, em uma praça, em uma área de vegetação nativa ou ao longo de uma praia, rio ou lago, estão sendo substituídas por experiências indiretas por meio 
de dispositivos eletrônicos (KUO, 2013; DWYRE, 2015; LOUV, 2016). Um estudo realizado pela Kaiser Family Foundation com 2.002 pessoas entre 8 e 18 anos mostra que as crianças estão gastando muito tempo em mídia eletrônica, cerca de 53 horas por semana, em comparação às décadas passadas (TOPPO, 2010).

O conceito de Transtorno de Déficit de Natureza está sendo cada vez mais discutido em vários centros de pesquisa, como o estudo da Faculdade de Ciências Agrícolas da Universidade de Illinois, EUA, sobre Consumidor e Ciências Ambientais, que analisou a melhor dosagem da natureza para combatê-lo. O estudo apontou que qualquer exposição às áreas naturais é importante, que todas as formas e quantidades de exposição são úteis e geram algum tipo de benefício (KUO, 2013).

Dwyre (2015), pesquisador da Universidade Fordham, destaca que a educação ambiental é uma abordagem fundamental para combater o Transtorno de Déficit de Natureza em pessoas, especialmente crianças, e que os educadores devem enfatizar, dentro e fora da sala de aula, a importância de se conectar com o mundo natural. O TDN impede que as crianças estimulem seus sentidos, prejudicando sua saúde mental, motora e intelectual, distanciando-as de si mesmas, e Louv (2016) destaca que fornecer contato com a natureza é tão fundamental quanto aprender conceitos para seu desenvolvimento, enfatizando que a natureza faz parte de seus direitos.

O poder do ambiente natural é tão transformador na vida humana que, de acordo com pesquisadores da Universidade do Kansas e da Universidade de Utah, o contato com o ambiente natural traz uma melhoria real e mensurável na criatividade e capacidade cognitiva das pessoas (ATCHLEY et al, 2012). Assim, o contato com áreas naturais pode ser uma ferramenta que ajuda os medicamentos ou pode substituí-los em alguns tratamentos de transtornos mentais, como o Déficit de Atenção e Hiperatividade, quando propostas mudanças nos hábitos das pessoas. Nesse contexto, as gerações futuras podem e devem usar o contato com a natureza para prevenir doenças físicas e mentais (ATCHLEY et al, 2012; LOUV, 2016).

Louv (2016, p. 25) ressalta que “[...] reduzir o déficit - refazer o elo quebrado entre os jovens e a natureza - é de nosso próprio interesse, não apenas porque a estética ou a justiça exigem, mas também porque nossa mentalidade, física e espiritual depende disso".

Segundo Kyttä (2003), quando as crianças brincam ao ar livre, gradualmente formam seu próprio relacionamento pessoal com o meio ambiente. Para as crianças, o relacionamento com o meio ambiente é formado por meio da interação ativa com um ambiente físico, social e cultural de importância singular e espacial. Segundo o autor, quando as crianças encontram 
recursos em um ambiente, elas o percebem como um lugar interessante e desafiador de aventura e exploração que as inspira a se movimentar e a encontrar ainda mais possibilidades. É um ciclo de formação de relacionamento positivo com o meio ambiente.

Portanto, é tão importante a inclusão de ações ambientais sustentáveis na vida humana desde a infância, para que ocorra a percepção do que é fundamental para se viver com boa qualidade de vida (ARAÚJO; SILVA, 2004).

Ambientes naturais são cenários ideais para integrar ambiente, sociedade e saúde, promovendo uma abordagem social e ecológica que contribua para a saúde e o bem-estar humanos, com base no contato com a natureza. Dessa forma, a saúde pública e a gestão ambiental têm um papel fundamental a desempenhar na conservação do meio ambiente e, nesse processo, há potencial para os parques e reservas naturais ganharem um papel expandido e atingirem e influenciarem as sociedades urbanas. É necessária uma abordagem socioecológica colaborativa entre os setores de saúde e gestão ambiental para garantir que o contato com a natureza seja parte integrante das estratégias de desenvolvimento sustentável para as comunidades urbanas locais e globais (MALLER et al, 2006).

Jacobi-Vessels (2013) menciona que as experiências em ambientes naturais oferecem múltiplos benefícios para as crianças pequenas, incluindo aumento da atividade física, redução da obesidade, melhor concentração e habilidades sociais aprimoradas.

Segundo Louv (2010), é possível atribuir medidas para reverter e resgatar gradualmente o interesse de jovens e crianças pelo contato com a natureza, visando pais e professores a despertar essa curiosidade. $\mathrm{O}$ autor destaca ainda que os espaços educacionais devem servir de ferramenta para fortalecer o relacionamento entre o ser humano e a natureza, para que atividades, experiências e aulas sejam mais produtivas e encorajadoras quando realizadas em áreas naturais.

É importante destacar a educação ao ar livre como uma metodologia para promover a interação e a integração dos indivíduos com o meio ambiente. Para Brookes (2002, 2003), a educação ao ar livre contribui para a compreensão alternativa das abordagens tradicionais do conhecimento, o papel da ciência, as maneiras pelas quais a natureza deve ser valorizada e as relações entre os indivíduos e a comunidade em geral. $\mathrm{O}$ autor também menciona que outras formas de educação tradicional não oferecem as mesmas oportunidades de aprendizagem que as propostas pela educação ao ar livre.

As formas tradicionais de educação geralmente envolvem a leitura de livros ou atividades em sala de aula. Essa forma de educação foi criada na era industrial para treinar 
pessoas para se tornarem melhores operários de fábrica. As formas holísticas de educação vão muito além e pensam no desenvolvimento de todos os aspectos dos indivíduos. É por isso que grandes organizações e instituições educacionais tradicionais estão começando a usar essa metodologia que também desenvolve relacionamentos, que devem ser intrapessoais, interpessoais e ecológicos (um apego ao meio ambiente) (PRIEST, 1999).

Segundo Priest (1999), com relação à associação entre educação ao ar livre e educação ambiental, é importante destacar que o ambiente fornece aos participantes a etapa em que o desafio está ocorrendo e, portanto, cria a experiência do aprendizado.

Auer (2008) destaca que a prática de educação ambiental, entre outros fatores, está relacionada a atividades práticas que permitem a valorização dos elementos essenciais do meio ambiente, despertando nos indivíduos a ideia de que é necessário cuidar do local em que vivem.

Louv (2016) evidencia que quando o contato com ambientes verdes é interrompido ou nunca estimulado, é percebido um aumento da obesidade infantil, um convívio social prejudicado por atitudes violentas e graves níveis de disfunções na saúde mental, com destaque para quadros depressivos, sendo estes os maiores malefícios à saúde humana derivados do TDN.

O poder dos ambientes naturais é tão transformador na vida humana que, segundo novos estudos, o contato com as áreas naturais pode ser uma ferramenta que auxilia os medicamentos ou até os substitui na realização de tratamentos de alguns transtornos mentais, como o transtorno de déficit de atenção e hiperatividade - TDAH, por propor mudanças em seus hábitos. Neste contexto, as futuras gerações podem e devem utilizar o contato com a natureza como forma de prevenção de doenças físicas e mentais (LOUV, 2016).

Cabe ressaltar que a inserção dessas medidas sustentáveis deve ser disposta com equidade para a população, permitindo vivências com a natureza para todos os níveis sociais e econômicos, trata-se de um direito de todos (ALBUQUERQUE, 2007). Desta maneira Louv (2016) ressalta que estar em contato com a natureza permite criar laços e conexões com si mesmo, estabelecer vínculos com áreas naturais na infância permite uma relação afetiva na vida adulta de um ser humano com relação à natureza.

De acordo com Louv (2010), é possível atribuir medidas para reverter e aos poucos resgatar o interesse dos jovens e crianças pelo contato com a natureza, direcionando os pais e professores a serem os despertadores desta curiosidade. $\mathrm{O}$ autor ainda aponta que os espaços educacionais devem servir como ferramenta para estreitar essa relação entre o ser humano e a natureza, de maneira que ações educacionais, vivências e aulas sejam mais produtivas e incentivadoras quando realizadas em áreas naturais. 
Jacobi-Vessels (2013) aponta que brincar na natureza pode ser uma estratégia de ensino eficaz e fornece memórias duradouras para os envolvidos. Nesse processo, pode haver alguma hesitação em abrir a porta da sala de aula, o que pode ser compreensível, mas as recompensas do tempo de aula gasto na natureza claramente superam possíveis dificuldades.

Entre os estudantes universitários, os sentidos externos, despertados em práticas fora da sala de aula, podem ser úteis no reforço de modalidades convencionais de aprendizado, como observação empírica e raciocínio de causa e efeito. Além disso, é possível quebrar as concepções dualísticas que separam as pessoas da natureza presentes nas análises ambientais, através de visões, sabores, toques e outros sentidos externos (AUER, 2008). Jacobi-Vessels (2013) complementa este enfoque ao mencionar que os espaços ao ar livre realizam com facilidade muitas atividades que ocorrem teoricamente em sala de aula.

Para Lugg (2007), um dos desafios da educação universitária é enfatizar a promoção do desenvolvimento sustentável na perspectiva educacional, promovendo currículos e metodologias inovadoras e interdisciplinares. Nesse sentido, como abordagem pedagógica, a educação ao ar livre tem algo efetivo a oferecer, pois está relacionada a uma aprendizagem holística e experimental, permitindo a integração de conhecimentos e habilidades em várias áreas.

O autor ressalta que a educação ambiental e ao ar livre, realizada em ambientes externos, pode ser significativa no desenvolvimento da sensibilidade e do conhecimento ambiental. Para Lugg (2007), esses conhecimentos e atitudes são componentes fundamentais para a formação de cidadãos alfabetizados em sustentabilidade.

Além dos processos educacionais, Maller (2006) destaca que, apenas observando a natureza, muitos aspectos da saúde e desenvolvimento humano podem ser marcadamente aprimorados. E também existem evidências de que existem benefícios terapêuticos a serem obtidos para os indivíduos porque eles estão em contato com a natureza (MALLER, 2006).

\section{Metodologia: Promoção da sustentabilidade e do bem-estar social através de aulas ao ar livre em um curso de ensino superior}

As interações entre os sistemas ambientais e humanos, apresentadas anteriormente, justificam um aumento das discussões sobre a temática ambiental nas últimas duas décadas, em que a procura por soluções aos problemas ambientais vem atingindo a esfera social, privada e pública. Todo esse anseio fez crescer uma demanda por profissionais ligados à área de 
sustentabilidade, recursos naturais, biodiversidade e processos produtivos limpos, como a carreira do gestor ambiental (CASTINO, 2017).

No Brasil, o primeiro curso superior de gestão ambiental foi criado em 2002, pela Escola Superior de Agricultura Luiz de Queiroz (ESALQ) da Universidade de São Paulo (CASTINO, 2017). E entendendo esta demanda e a importância de se formar profissionais na área ambiental, o Centro Universitário UNIFAAT (na época Faculdades Atibaia - FAAT) teve em 2014 o ingresso de sua primeira turma do curso de ensino superior tecnológico em Gestão Ambiental. Este curso atua, principalmente, no entendimento das relações existentes entre o ser humano e a natureza, procurando soluções aos impactos decorrentes desta relação quando realizada sem planejamento e tendo como principal objetivo formar profissionais (gestores ambientais) "com ética, visão crítica e forte consciência ambiental para atuar no planejamento, gerenciamento e execução de diagnósticos e avaliações de impactos socioambientais" (UNIFAAT, 2018).

O curso conta com uma carga horária de 2220 horas, dividida em 4 semestres e em 36 disciplinas obrigatórias, 6 disciplinas optativas e atividades complementares. Dentre as disciplinas obrigatórias, cabe destacar: Projeto Socioambiental Integrado no Setor Público, Projeto Socioambiental Integrado no Setor Privado, Projeto Socioambiental Integrado em Unidades de Conservação e Projeto Socioambiental Integrado no Terceiro Setor, que apresentam aulas práticas incluídas em seus planos de ensino. Estas disciplinas têm como finalidade estudar e analisar de forma teórico-prática as relações existentes entre a problemática socioambiental e o manejo de recursos naturais renováveis e não renováveis, além de auxiliar na identificação e análise de problemas socioambientais concretos e na elaboração de suas possíveis soluções em suas temáticas (UNIFAAT, 2018).

\section{Análise e Discussão dos Resultados}

As aulas práticas aconteceram por meio de visitas técnicas que envolveram aulas de campo em estações de tratamento de esgoto e água, usina de reciclagem de resíduos sólidos, organizações não governamentais - ONGs ambientais, viveiros de mudas nativas, empresas com processos produtivos e produtos sustentáveis, áreas protegidas -, unidades de conservação e propriedades rurais orgânicas.

A coordenação do curso, juntamente com os professores, propôs aulas ao ar livre por compreender que estas integram os alunos do curso de gestão ambiental a prováveis locais de atuação, possibilitando um maior contato com profissionais que atuam na área ambiental ecológica e também conhecer novas ferramentas e metodologias de manejo utilizadas em 
processos que envolvam a gestão ambiental em áreas naturais. Estas aulas/visitas também têm como objetivo auxiliar o estudante na compreensão de como a teoria observada em sala de aula se relaciona com a prática, vivenciando a realidade local e como os fatores ambientais, sociais e econômicos interagem nos diferentes contextos visitados.

Cada localidade proporcionou experiências diferenciadas aos alunos, oferecendo-lhes novas formas de lidar com ambientes naturais, abordando as teorias abordadas na sala de aula com experiências práticas ao ar livre (HOEFEL et al, 2017). A maioria das aulas ao ar livre foi realizada em diferentes áreas protegidas como Unidades de Conservação com Proteção Total (Monumento Natural da Pedra Grande Natural - Atibaia / SP, Parque Nacional do Itatiaia Itatiaia / RJ (Figura 1), Parque Municipal da Grota Funda - Atibaia / SP, Parque Estadual da Caverna do Diabo - Vale da Ribeira / Parque Natural Municipal Fazenda do Carmo - São Paulo /SP) e Unidades de Conservação de Uso Sustentável (Área de Proteção Ambiental do Sistema Cantareira e Fernão Dias - Serra do Lopo - Extrema / MG (Figura 2), Área de Proteção Ambiental do Bairro da Usina - Atibaia / SP e Reserva Particular do Patrimônio Natural Fazenda Serrinha - Bragança Paulista / SP).

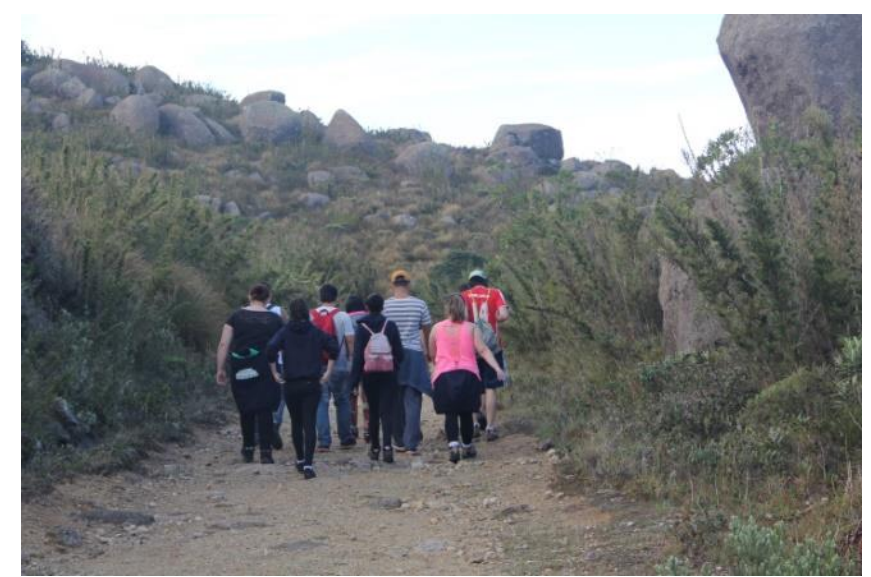

Figura 1 - Estudo de Campo realizado no Parque Nacional do Itatiaia/RJ. Fotografia: Micheli Kowalczuk Machado (2016). 


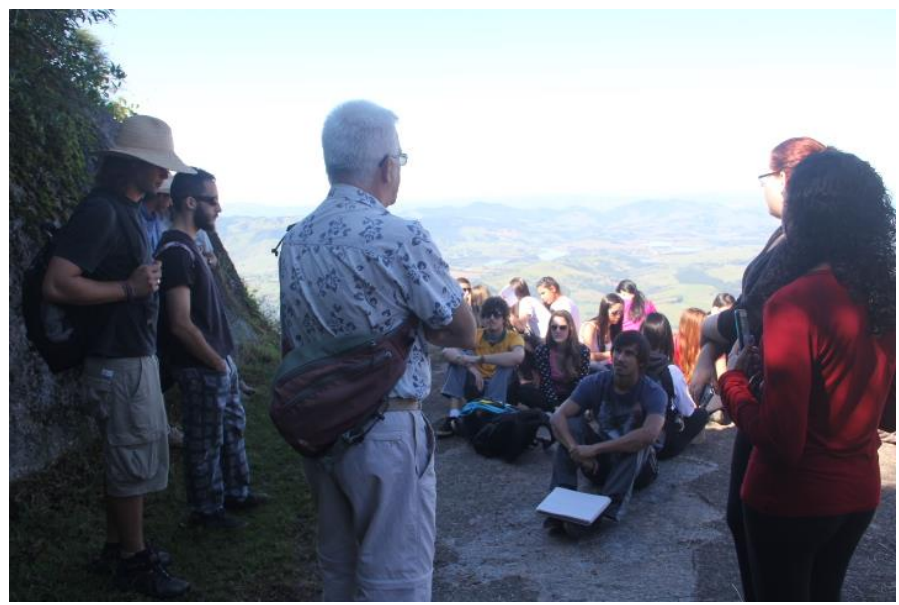

Figura 2 - Estudo de Campo realizado na Serra do Lopo - Extrema /MG. Fotografia: Micheli Kowalczuk Machado (2016)

Essas escolhas visam a ajudar os alunos a entender que esses espaços têm uma contribuição importante para a conservação dos recursos naturais, para a carreira do gerente ambiental e para a vida pessoal de todo ser humano. Também foram realizadas aulas de campo em fazendas (Fazenda da Família Orgânica e propriedades Agroecológicas em Piracaia - SP (Figura 3)), áreas privadas de conservação ambiental (Legado das Águas Reserva Votorantim - Juquiá Tapiraí e Miracatu / SP (Figura 4)) e uma comunidade rural tradicional (Quilombo Ivaporunduva / SP) (UNIFAAT, 2018).

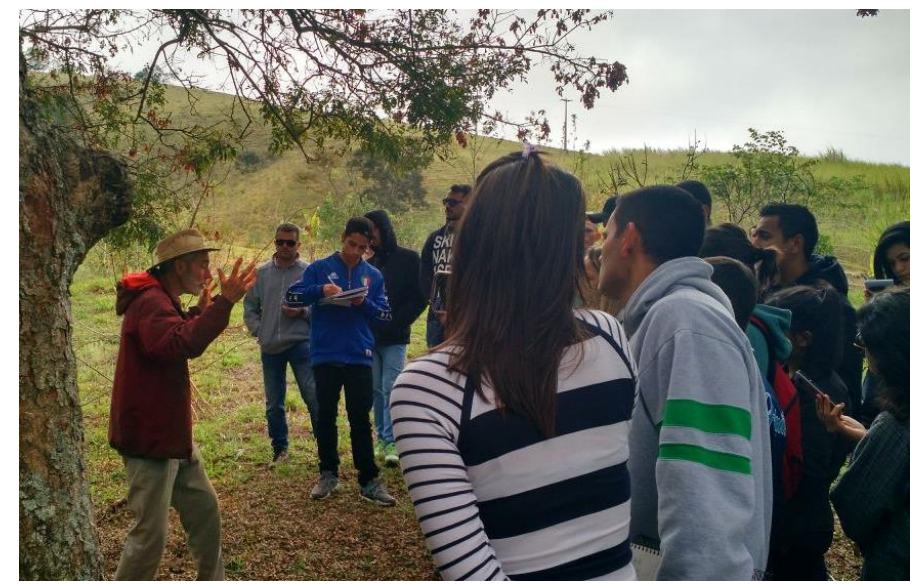

Figura 3 - Estudo de Campo realizado no Sítio Família Orgânica - Piracaia/SP. Fotografia: Giovana Dominicci Silva (2017). 


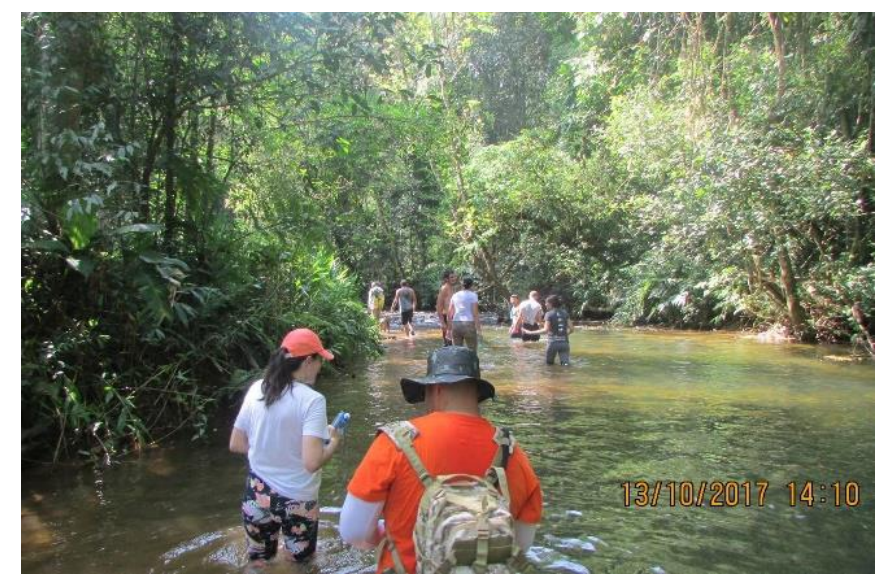

Figura 4 - Estudo de campo Legado das Águas Reserva Votorantim - Juquiá, Tapiraí e Miracatu/SP. Fotografia: Micheli Kowalczuk Machado (2017).

Com a realização dessas atividades, espera-se que o gestor ambiental possa atuar no gerenciamento, planejamento e implementação de atividades de diagnóstico, avaliação de impacto, com o objetivo de melhorar a qualidade e a sustentabilidade ambiental em processos educacionais envolvendo relacionamento entre seres humanos e o meio ambiente. Além de colaborar com políticas públicas voltadas à melhoria da qualidade de vida e preservação da natureza (UNIFAAT, 2018; HOEFEL et al; 2017).

Essas atividades ao ar livre confirmam as discussões realizadas neste trabalho sobre sustentabilidade, qualidade de vida e transtorno de déficit de natureza, uma vez que alunos e professores identificaram aspectos positivos em relação à mudança de comportamento e qualidade de vida decorrentes das aulas ao ar livre propostas pelo curso. Diante de experiências diretas com a natureza, os alunos demonstram durante as aulas o crescimento pessoal e profissional que motivam ações benéficas ao meio ambiente (UNIFAAT, 2018).

A análise dessa experiência também expõe a integração entre os alunos e as aulas externas, mostrando benefícios sociais e educacionais quando realizados em centros educacionais de ensino superior, por exemplo. Também é possível identificar que as aulas ao ar livre podem ser usadas como ferramentas de (re) conexão de seres humanos com ambientes naturais e prevenção de diversos problemas associados ao transtorno de déficit de natureza, além de promover processos educacionais sustentáveis.

\section{Considerações Finais}

Os conceitos abordados neste trabalho evidenciam que a relação entre o ser humano e meio ambiente (espaços naturais) deve ser incentivada não apenas em espaços educacionais, 
mas em outros círculos de convivência, envolvendo, principalmente, crianças e jovens, por estas ações incentivarem as relações sociais e a formação de seres humanos mais conscientes com relação à sustentabilidade, aos recursos naturais e ao seu papel na sociedade.

Assim, neste estudo, observa-se a importância das atividades na natureza, das experiências individuais e grupais ao ar livre, a fim de combater o transtorno de déficit da natureza, promover benefícios à qualidade de vida e à saúde em geral. A análise baseada nas aulas ao ar livre do curso de Gestão Ambiental da UNIFAAT permitiu uma maior compreensão dos benefícios gerados por essas experiências nos cursos de ensino superior e como eles geram mudanças na vida pessoal e profissional do aluno.

Evidencia-se também que o contato com áreas naturais e protegidas e com propriedades rurais estimula benefícios à saúde física, mental e social dos envolvidos e das pessoas próximas a eles, para estabelecer um vínculo emocional com esses espaços naturais e com causas ambientais e sustentabilidade em geral.

\section{Referências}

ALBUQUERQUE, B. P. As relações entre o homem e a natureza e a crise socioambiental. 2007. Dissertação. Escola Politécnica de Saúde Joaquim Venâncio, Fundação Oswaldo Cruz (Fiocruz), Rio de Janeiro, 2007.

AMARAL, R.; GUTJAHR, M. R. A influência humana nos Desastres Naturais e suas consequências: desastres naturais. São Paulo: IG/SMA, 2011. Disponível em: http://arquivos.ambiente.sp.gov.br/publicacoes/2016/12/8-DesastresNaturais.pdf. Acessoem: 06 jan. 2018.

ARAUUJO, G. C.; SILVA, R. P. Desenvolvimento Sustentável do Meio Ambiente: Estudo no Instituto Souza Cruz. In: CONGRESSO BRASILEIRO DE EXTENSÃO UNIVERSITÁRIA, 2., 2014, Belo Horizonte. Anais [...] Belo Horizonte: Faculdades Integradas Rui Barbosa de Andradina/SP - FIRB, 2014. p. 12-15. Disponível em:

https://www.ufmg.br/congrext/Meio/Meio57.pdf Acesso em:06 jan. 2018.

ATCHLEY, R. A.; STRAYER D. L.; ATCHLEY, P. Creativity in the Wild: Improving Creative Reasoning through Immersion in Natural Settings. PLoS ONE [on line], v. 7, n.12, p.1-3, dez. 2012.

AUER, M. R. Sensory Perception, Rationalism and Outdoor Environmental Education. International Research in Geographical and Environmental Education [on line], v. 17, n. 1, p. 6-12, 2008.

BARBOSA, S. R. C. S. Qualidade de vida e necessidades sentidas: uma aproximação teórica. Humanitas, Campinas, v. 1, n. 2, p. 39-62, 1998. 
BROOKES, A. Lost in the Australian bush: Outdoor education as curriculum. Journal of Curriculum Studies [on line], v. 34, n. 4, p. 405-425, 2002.

BROOKES, A. A critique of Neo-Hahnian outdoor education theory. Part two: "The fundamental attribution error" in contemporary outdoor education discourse. Journal for Adventure Education and Outdoor Learning [ on line], v. 3, n. 2, 119-132, 2003.

CASTINO, R. Cursos da USP: Gestão Ambiental atua na relação homem-natureza: Ampla atuação, alto índice de empregabilidade e caráter multidisciplinar são as principais características. Jornal da USP [on line], 23 nov. 2017. Disponível em: [on line] http://jornal.usp.br/universidade/cursos-da-usp-gestao-ambiental-atua-na-relacao-homemnatureza/ Acesso em: 12 jan 2018.

DWYRE, V. J. Nature Deficit Disorder and the Need for Environmental Education. Thesis, Fordham University, 2015.

GUIMARÃES, E.; PELLIN, A. BiodiverCidade: Desafios e Oportunidades na Gestão de áreas Protegidas Urbanas. Matrix, São Paulo, 2015.

HOEFEL, J. L.; SILVA, G. D.; MACHADO, M. K. Projeto Socioambiental Integrado: práticas de formação e extensão. UNIFAAT, Atibaia, 2017.

JACOBI-VESSELS, J. L. Discovering Nature: The Benefits of Teaching Outside of the Classroom. Dimensions of Early Childhood [on line], v. 41, n.3, p. 4-10, 2013.

KUO, F. E. M. Nature-deficit disorder: evidence, dosage, and treatment. Journal of Policy Research in Tourism, Leisure and Events [on line], v.5, n.2, p.172-186, 2013.

KYTTÄ, M. Children in outdoor contexts: affordances and independent mobility in the assessment of environmental child friendliness. Helsinki University of Tehncology, Centre for Urban and Regional Studies, Espoo, 2003.

LOUV, R. Do Our Kids Have Nature-Deficit Disorder? Educational Leadership [on line], v. 67, n. 4, p. 24-30, 2010. Disponível em: http://forestschoolportfolio.com/wp-

content/uploads/2015/08/DoOurKidsHaveNature-DeficitDisorderLouv.pdf. Acesso em: 07 jan. 2018 .

LOUV, R. A Última Criança na Natureza. Resgatando as Nossas Crianças do Transtorno do Deficit de Natureza. São Paulo: Aquariana, 2016.

LUGG, A. Developing sustainability-literate citizens through outdoor learning: possibilities for outdoor education in Higher Education. Journal of Adventure Education and Outdoor Learning [on line], v. 7, v.2, p. 97-112, 2007.

MALLER, C.; TOWNSEND, M.; PRYOR, A.; BROWN, P.; St LEGER, L. Healthy nature healthy people: 'contact with nature' as an upstream health promotion intervention for populations. Health Promotion International [on line], v.21, n. 1, p. 45-54, 2006.

MILLENNIUM ECOSYSTEM ASSESSMENT. 2003. Disponível em: www.millenniumassessment.org/en/Framework.aspx. Acesso em: 6 jan. 2018. 
PAULO, R. F. O Desenvolvimento Industrial e o Crescimento Populacional como Fatores Geradores do Impacto Ambiental. Veredas do Direito, Belo Horizonte, v. 7, n.13/14, p. 173189, ago. 2010. Disponível em:

http://www.domhelder.edu.br/revista/index.php/veredas/article/view/180/153. Acesso em:05 jan. 2018.

PELLIN, A.; CARVALHO, G.; REIS, J. C.; PELLIN, A. Gestão do uso público em unidades de conservação urbanas: o caso do Parque Estadual da Pedra Branca (RJ). Revista Brasileira de Ecoturismo, São Paulo, v. 7, n. 2, p.344-373, maio./jul. 2014.

PRIEST, S. The Semantics of Adventure Education. Adventure Education. In: Miles JC, Priest (eds) Adventure Programming, Venture Publishing Inc, State College, PA, p. 111$115,1999$.

SCHULTZ, P. W.; SHRIVER, C.; TABANICO, J. J.; KHAZIAN, A. M. Implicit connections with nature. Journal of Environmental Psychology [on line], v. 24, p.31-42, 2004.

SILVA, K. C.; SAMMARCO, Y. M. Relação Ser Humano e Natureza: Um Desafio Ecológico e Filosófico. Monografias Ambientais, Santa Maria, v. 14, n. 2, p. 01-12, maio/ago. 2015.

SUAREZ, C. F. S.; SEIXAS, S. R. C. S.; HOEFFEL, J. L. M.; FADINI, A. A. B.; SILVA, G. D. Reflexões Sobre Turismo Sustentável e Qualidade de Vida em Unidades de Conservação. Qualidade de Vida e Turismo na Sociedade Contemporânea. In: HOEFFEL, J. L. M.; FADINI, A. A. B.; SEIXAS, S. R. C. S. (eds.) Sustentabilidade, Qualidade de Vida e Identidade Local: Olhares sobre as APA's Cantareira (SP) e Fernão Dias (MG). São Carlos: RiMa Editora/FAPESP, 2010, p. 135-147.

TILBURY, D. Education for Sustainable Development - An Expert Review of Processes and Learning. UNESCO, Paris, 2011.

TOPPO, G. Kids' electronic media use jumps to 53 hours a week. USA today [on line], 2010. Disponível em: http://usatoday30.usatoday.com/tech/news/2010-01-201Avideokids20_ST_N.htm?obref=obnetwork. Acesso em: 27 jun. 2018.

UNIFAAT - Centro Universitário. Cursos de Graduação: Gestão Ambiental, 2018. Disponível em: http://www.faat.com.br/site/curso_int.asp?num_curso=607. Acesso em: 03 jan. 2018.

UNITED NATIONS (UN). The 2030 agenda for sustainable development, 2015. Disponível em: https://sustainabledevelopment.un.org/content/documents/21252030\%20Agenda\%20for\%20S ustainable\%20Development\%20web.pdf. Acesso em: 10 nov. 2017. 